\title{
BEBERAPA FAKTOR YANG MEMPENGARUHI KEPUTUSAN PEMBELIAN PULSA TELKOMSEL PADA MAHASISWA UNMAS DENPASAR PSDKU MATARAM
}

\author{
SILFIA HERLINA ${ }^{1)}$, MADE SUMA WEDASTRA ${ }^{2)}$, I DEWA GEDE SUARTHA ${ }^{3)}$ \\ Fakultas Pertanian UNMAS Denpasar PSDKU Mataram \\ e-mail : ${ }^{1)}$ silfiaherlina120789@gmail.com, ${ }^{2)}$ madesumawedastra17@gmail.com, \\ 3)dsuartha@ymail.com
}

\begin{abstract}
ABSTRAK
Penelitian ini bertujuan untuk mengetahui faktor-faktor yang mempengaruhi pegambilan keputusan pembelian pulsa telkomsel pada Mahasiswa UNMAS Denpasar PSDKU Mataram. Penelitian merupakan penelitian assosiatif, pengambilan sampel dilakukan secara purposive sampling terhadap 100 responden Mahasiswa, data dianalisis dengan analisis regresi berganda.

Hasil penelitian menunjukkan bahwa 1). Secara parsial Kebutuhan konsumen (X1) dan referensi teman (X3) berpenaruh terhadap keputusan pembelian pulsa telkomsel. Hal ini ditunjukkan dari $\mathrm{T}$ test $(\mathrm{x} 1)=2,341>\mathrm{t}$ table $\alpha 0,05 / 2(1,987)$, dan $\mathrm{T}$ test $(\mathrm{x} 3)=2,508>\mathrm{t}$ table $\alpha 0,05 / 2(1,987)$, sedangkan variabel pengaruh keluarga (X2), interaksi social konsumen (X4) dan jenis merek (X5) berpengaruh terhadap keputusan pembelian pulsa, tetapi tidak signifikan, 2). Secara simultan kebutuhan konsumen (X1), pengaruh keluarga (X2), referensi teman (X3), interaksi social konsumen (X4) dan jenis merek (X5) berpengaruh terhadap keputusan pembelian pulsa. Hal ini ditunjukan dari $\mathrm{F}$ test $(50,130)>\mathrm{F}$ table $(1,85)$, dengan nilai koefisien determinasi $\left(\mathrm{R}^{2}\right)=0,935$, yang berarti bahwa besarnya pengaruh variabel bebas terhadap variabel terikat sebesar 93,50\% dan 6,50\% dipengaruhi oleh faktor di luar model, 3). Faktor Referensi Teman merupakan faktor yang dominan terhadap keputusan membeli pulsa Telkomsel pada kalangan mahasiswa UNMAS Denpasar PSDKU Mataram
\end{abstract}

Kata kunci : keputusan pembelian, pulsa telkomsel.

\section{ABSTRACT}

This study aims to determine the factors that influence the decision to purchase Telkomsel pulses on UNMAS Denpasar PSDKU Mataram students. The research was an associative study, the sampling was done by purposive sampling of 100 student respondents, the data were analyzed by multiple regression analysis.

The results showed that 1). Partially consumer needs (X1) and friend references (X3) affect the decision to buy Telkomsel pulses. This is indicated from T test $(x 1)=2,341>t$ table $\alpha 0.05 / 2(1,987)$, and $T$ test $(x 3)=2,508>t$ table $\alpha 0.05 / 2$ (1,987), while the family influence variable (X2), consumer social interaction (X4) and type of brand (X5) influence the credit purchase decision, but not significantly, 2). Simultaneously the needs of consumers $(X 1)$, the influence of family (X2), reference friends $(X 3)$, consumer social interaction (X4) and type of brand (X5) influence on credit purchase decisions. This is shown from the $F$ test $(50,130)>F$ table $(1.85)$, with the coefficient of determination $(R 2)=0.935$, which means that the magnitude of the influence of independent variables on the dependent variable is $93.50 \%$ and $6.50 \%$ is influenced by factors outside the model, 3). Friend's Reference Factor is the dominant factor in the decision to buy Telkomsel pulses among UNMAS Denpasar PSDKU Mataram students

Keywords: purchasing decisions, Telkomsel pulses. 


\section{PENDAHULUAN}

\section{Latar Belakang}

Pemasaran berkembang dengan pesat dan memahami perilaku konsumen menjadi salah satu strategi dalam keberhasilan memasarkan produk. Menghasilkan suatu produk yang diinginkan konsumen akan mengefisienkan kegiatan pemasaran, melalui pemahaman perilaku konsumen akan diperoleh informasi bagaimana konsumen mengembangkan sejumlah alternatif dalam pembeliannya.

Informasi akan menjadi fokus kegiatan pemasaran untuk mendesain produk, harga, bauran promosi, distribusi sampai dengan sistem pelayanan sesuai dengan yang diperlihatkan konsumen melalui perilakunya.

Menurut Schiffman, 2007 dalam Suprapti, (2010:2), perilaku konsumen dapat didefinisikan sebagai perilaku yang ditunjuk oleh konsumen dalam mencari, membeli, menggunakan, mengevaluasi, dan membuang produk dan jasa yang diharapkan akan memenuhi berbagai kebutuhannya

Saat ini, persaingan antar operator terjadi dalam hal pricing, brand, cakupan wilayah jaringan, distribusi, teknologi, layanan nilai tambah, dan kualitas jaringan.Letak kekuatan dari Telkomsel ada pada kualitas jaringan, jangkauan jaringan, dan mereknya.Pesaing telepon seluler kini datang tidak hanya dari produk sejenis, namun juga dari layanan telepon tetap tanpa kabel.

Adapun jumlah pengguna jasa seluler masing-masing operator di Indonesia Tahun 2016 - 2018 ditunjukkan pada Table 1.

Tabel 1. Jumlah Pengguna Jasa Seluler di Indonesia Tahun 2016-2018

\begin{tabular}{|l|l|l|l|}
\hline \multicolumn{1}{|c|}{ Nama jasa seluler } & \multicolumn{1}{|c|}{$\mathbf{2 0 1 6}$ (juta) } & \multicolumn{1}{|c|}{$\mathbf{2 0 1 7}$ (juta) } & \multicolumn{1}{c|}{$\mathbf{2 0 1 8}$ (juta) } \\
\hline PT. TELKOMSEL & 157,4 & 163 & 196,3 \\
\hline PT. INDOSAT & 80,5 & 97 & 64,1 \\
\hline PT. EXCELCOMINDO & 42 & 46 & 52,9 \\
\hline HUTCHISON 3 INDONESIA & 11,5 & 13 & 17,8 \\
\hline PT. SMARTFREND & 12 & 11,5 & 15 \\
\hline
\end{tabular}

Sumber : Kontan.co.id, seular.id, databoks.katadata.co.id

Berdasarkan Tabel 1 terlihat jasa seluler yang memiliki pelanggan terbesar adalah PT. Telkomsel dengan jumlah yang semakin besar setiap tahunnya, urutan kedua adalah PT. indosat meskipun pada akhir tahun 2018 mengalami penurunan yang sangat drastis karena menurut manajer pemasarannya bahwa indosat masih dipusatkan di pulau Jawa, urutan ketiga adalah PT. Excel Axiata, urutan keempat adalah Tri dan terakhir adalah Smartfrend.

Sedangkan untuk Jumlah kartu yang berhasil diregistrasi dengan divalidasinomor induk kependudukan dan kartu keluarga oleh beberapa operator hingga akhir tahun 2018 ditunjukkan pada Tabel 2

Tabel 2. Jumlah kartu yang berhasil diregistrasi dan divalidasi oleh masing-masing operator seluler di Indonesia

\begin{tabular}{|l|r|}
\hline \multicolumn{1}{|c|}{ Nama jasa seluler } & Jumlah kartu \\
\hline Telkom Indihome & 54.671 \\
\hline XL Axiata & 42.362 .769 \\
\hline Smartfrend & 588.086 \\
\hline Sampoerna Telekomunikasi Indonesia & 8.776 \\
\hline Telkomsel & 139.934 .665 \\
\hline Indosat Ooredo & 100.538 .309 \\
\hline Hutchison 3 Indonesia (TRI) & 12.782 .993 \\
\hline Total & 296.270 .269 \\
\hline
\end{tabular}

Sumber : Kontan.co.id

Berdasarkan data jumlah kartu yang berhasil diregistrasi dan divalidasi tersebut di atas menunjukkan bahwa jumlah pengguna jasa seluler banyak yang memiliki lebih dari satu kartu handphone dan adapula yang menggunakan satu kartu identitas kependudukan untuk mendaftar lebih dari satu kartu handphone pada jasa seluler tertentu, oleh karena itu sangat penting sekali dari pihak jasa operator seluler membedakan dan memberikan alternatif kartu yang tidak hanya menggunakan kartu identitas saja agar tidak terjadi double registrasi dengan kartu yang sama. 
Mahasiswa Universitas Mahasaraswati Denpasar Kampus Mataram adalah mahasiswa yang mayoritasnya berasal dari luar daerah seperti daerah Sumba, Flores dan Kupang.Sebagian besar dari mereka menggunakan jasa seluler Telkomsel. Hal ini terjadi karena di tempat asal mereka satu-satunya jaringan dengan sinyal yang kuat dan mendukung adalah layanan jasa telkomsel, kebiasaan ini pula membawa mereka untuk tetap dan bertahan memilih jasa seluler telkomsel sebagai pilihan terbaik untuk tetap menjaga komunikasi mereka dengan sanak keluarga di daerah mereka berasal.

Berdasarkan data dan kondisi yang terjadi maka inilah yang mengilhami peneliti untuk melakukan penelitian yang berjudul Beberapa FaktorYang Mempengaruhi Pembelian Pulsa Telkomsel Pada Kalangan Mahasiswa Universitas Mahasaraswati Mataram.

\section{Rumusan Penelitian}

a. Apakah terdapat pengaruh secara parsial terhadap beberapa faktor yang mempengaruhi keputusan pembelian pulsa Telkomsel pada kalangan mahasiswa universitas Mahasaraswati Mataram

b. Apakah terdapat pengaruh secara simultan terhadap beberapa faktor yang mempengaruhi keputusan pembelian pulsa Telkomsel pada kalangan mahasiswa universitas Mahasaraswati Mataram

c. Apakah terdapat pengaruh paling dominan terhadap beberapa faktor yang mempengaruhi keputusan pembelian pulsa Telkomsel pada kalangan mahasiswa universitas Mahasaraswati Mataram

\section{Tujuan Penelitian}

a. Secara parsial, Mencari signifikansi beberapa faktor yang mempengaruhi keputusan pembelian pulsa Telkomsel pada kalangan mahasiswa universitas Mahasaraswati Mataram

b. Secara simultan, Mencari signifikansi beberapa faktor yang mempengauhi keputusan pembelian pulsa Telkomsel pada kalangan mahasiswa universitas Mahasaraswati Mataram

c. Mencari signifikansi yang paling dominan dari beberapa faktor yang mempengaruhi keputusan pembelian pulsa Telkomsel pada kalangan mahasiswa universitas Mahasaraswati Mataram

\section{METODE PENELITIAN}

Penelitian ini merupakan penilitian asosiatif atau sebab akibat yang dilaksanakan terhadap 100 responden mahasiswa Universitas Mahasaraswati Denpasar Kampus Mataram yang berasal dari luar daerah yaitu dari sumba dan Flores, penarikan sampel secara porsive sampling yang diketahui menggunakan kartu Telkomsel dan tidak berpindah ke jasa seluler yang lain dilaksanakan pada bulan Nopember 2018.

Tehnik pengumpulan data berupa angket yang digunakan dalam sejumlah pertanyaan tertulis dan wawancara, alat pengumpulan data adalah dengan menyebar kuesioner. Variable di ukur dengan skala likert dan pengujian hipotesis menggunakan analisis regresi linear berganda.

\section{HASIL PENELITIAN DAN PEMBAHASAN}

Tabel 2. Hasil Regresi Linear Berganda

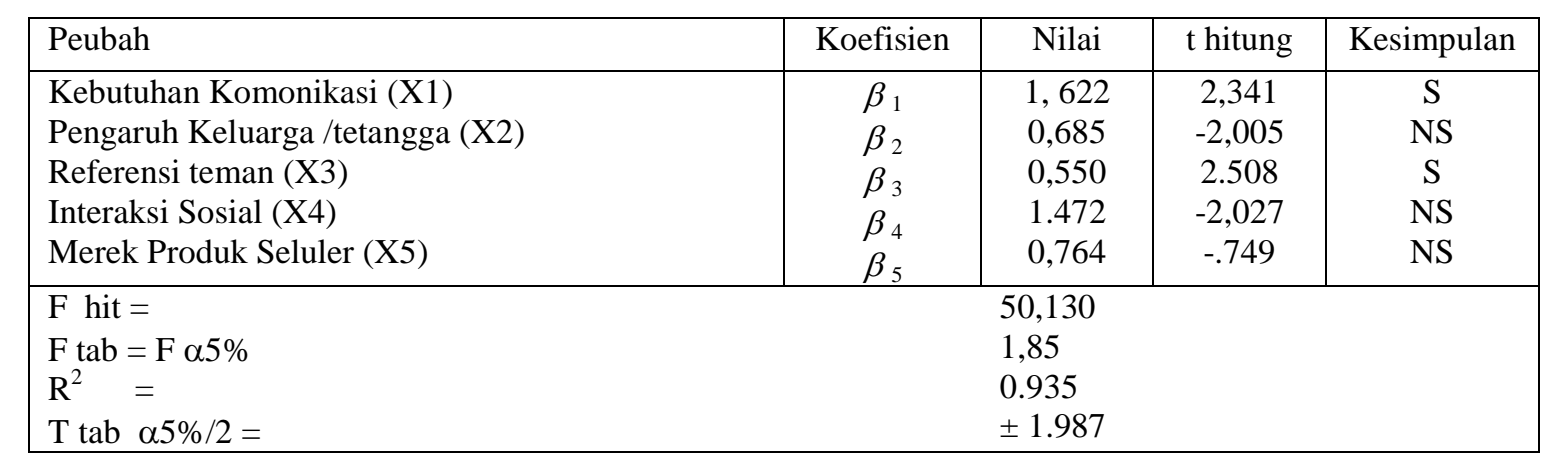

Sumber : Lampiran Diolah 


\section{Kebutuhan Komunikasi Konsumen (X1)}

Hasil pengujian hipotesis Kebutuhan komunikasi konsumen menunjukkan nilai $\mathrm{t}_{\text {hitung }}$ sebesar 2.341 lebih besar dari nilai $t$ tabel dengan $\alpha 0.05 / 2=1.987$ (Sugiyono, 2009:372). Kenyataan ini berarti bahwa hipotesis observasi (Ho) ditolak dan menerima hipotesis alternatif (Ha). Dengan demikian dapat disimpulkan bahwa secara parsial kebutuhan komunikasi konsumen berpengaruh secara positif dan signifikan terhadap beberapa faktor yang mempengaruhi keputusan pembelian pulsa Telkomsel pada kalangan Mahasiswa UNMAS Denpasar PSDKU Mataram

Kedua variabel ini saling terkait dan searah artinya ketika Kebutuhan komunikasi konsumen meningkat maka keputusan pembelian pulsa Telkomsel juga meningkat.

\section{Pengaruh Keluarga (X2)}

Variabel Pengaruh keluarga memiliki nilai sebesar -2.005nilai $t_{\text {hitung }}$ ini lebih kecil jika dibandingkan dengan nilai $t_{\text {tabel }}$ dengan $\alpha 0.05 / 2= \pm 1.987$ (Sugiyono, 2009:372). Dari hasil tersebut, maka hipotesis observasi (Ho) diterima dan hipotesis alternative (Ha) ditolak. Dengan demikian dapat disimpulkan bahwa Pengaruh keluarga tidak berpengaruh secara signifikan terhadap beberapa faktor yang mempngaruhi keputusan membeli pulsa Telkomsel pada kalangan Mahasiswa UNMAS Denpasar PSDKU Mataram.

\section{Referensi Teman Konsumen (X3)}

Dari nilai $\mathrm{t}_{\text {hitung }}$ pada variabel Referensi teman konsumenmemiliki nilai sebesar 2.508 , nilai $\mathrm{t}_{\text {hitung }}$ ini lebih besar jika dibandingkan dengan nilai $t_{\text {tabel }}$ dengan $\alpha$ 0.05/2 $= \pm 1.987$ (Sugiyono, 2009:372). Dari hasil tersebut, maka hipotesis observasi (Ho) ditolak dan hipotesis alternative (Ha) diterima. Dengan demikian dapat disimpulkan bahwa Referensi teman konsumen berpengaruh secara positif dan signifikan terhadap beberapa faktor yang mempengaruhi keputusan membeli pulsa Telkomsel pada kalangan Mahasiswa UNMAS Denpasar PSDKU Mataram

Kedua variabel ini saling terkait dan searah artinya Referensi teman konsumen mempengaruhi tingkat pembelian pulsa Telkomsel pada kalangan mahasiswa Universitas Mahasaraswati Denpasar Kampus Mataram. Jika Referensi teman konsumen semakin baik atau terpenuhi maka tingkat keputusan pembelian kartu Telkomsel pada kalangan mahasiswa UNMAS Denpasar PSDKU Mataram akan semakin baik atau meningkat.

\section{Interaksi Sosial Konsumen (X4)}

Nilai $\mathrm{t}_{\text {hitung }}$ pada variabel Interaksi sosial konsumenmemiliki nilai sebesar -2.027nilai $\mathrm{t}_{\text {hitung }}$ ini kecil jika dibandingkan dengan nilai $\mathrm{t}_{\text {tabel }}$ dengan $\alpha$ 0.05/2 $= \pm 1.987$ (Sugiyono, 2009:372). Dari hasil tersebut, maka hipotesis alternatif (Ha) ditolak dan hipotesis observasi (Ho) diterima. Dengan demikian dapat disimpulkan bahwa Interaksi sosial konsumen tidak berpengaruh secara signifikan terhadap keputusan pembelian pulsa Telkomsel pada kalangan mahasiswa UNMAS Denpasar PSDKU Mataram

\section{Merek (X5)}

Nilai $\mathrm{t}$ hitung pada variabel Merek produk memiliki nilai sebesar -0.749 nilai $\mathrm{t}$ hitung ini kecil jika dibandingkan dengan nilai $\mathrm{t}_{\text {tabel }}$ dengan $\alpha$ 0.05/2 $= \pm 1.987$ (Sugiyono, 2009:372). Dari hasil tersebut, maka hipotesis alternatif (Ha) ditolak dan hipotesis observasi (Ho) diterima.Dengan demikian dapat disimpulkan bahwa Merek produk tidak berpengaruh secara positif dan signifikan terhadap keputusan pembelian PULSA Telkomsel pada kalangan mahasiswa UNMAS Denpasar PSDKU Mataram 


\section{SIMPULAN}

Dari hasil penelitian dapat disimpulkan sebagai berikut :

1. Secara parsial yang diidentifikasi berpengaruh signifikan terhadap keputusan pembelian pulsa Telkomsel pada kalangan Mahasiswa UNMAS Denpasar PSDKU Mataram adalah Kebutuhan konsumen (X1) dan referensi teman (X3). Hal ini ditunjukkan dari $\mathrm{T}$ test $(\mathrm{x} 1)=2,341>\mathrm{t}$ table $\alpha 0,05 / 2(1,987)$, dan $\mathrm{T}$ test $(\mathrm{x} 3)=2,508>\mathrm{t}$ table $\alpha 0,05 / 2(1,987)$, sedangkan variabel pengaruh keluarga (X2), interaksi social konsumen (X4) dan jenis merek (X5) berpengaruh terhadap keputusan pembelian pulsa, tetapi tidak signifikan.

2. Secara simultan Kebutuhan konsumen (X1), pengaruh keluarga (X2), refeerensi teman (X3), interaksi social konsumen (X4) dan jenis merek (X5) berpengaruh terhadap keputusan pembelian pulsa. Hal ini ditunjukan dari F test $(50,130)>\mathrm{F}$ table $(1,85)$

3. Faktor Referensi Teman merupakan faktor dominan terhadap keputusan membeli pulsa Telkomsel pada kalangan mahasiswa UNMAS Denpasar PSDKU Mataram

\section{DAFTAR PUSTAKA}

Kontan.co.id, seular.id, databoks.katadata.co.id

Kotler, P. 2004. Manajemen Pemasaran. Erlangga : Jakarta.

Mowen, J., C \& Minor, M. 2002. Perilaku Konsumen, Alih Bahasa: Lina Salim, Edisi 5, Erlangga Jakarta.

Nazir, M. 2003. Metode Penelitian, Ghalia Indonesia Jakarta

Schiffman, L., G \& Kanuk L., L. 2000, Consumer Behavior, Fifth Edition, New Jersey: Prentice-Hall Inc Simamora, Bilson. 2004.Manajemen Sumber Daya Manusia, Edisi III, Jakarta: STIE YKPN

Sugiyono,2008. Metode Penelitian Kualitatif Dan Kuantitatif. Alfabeta Bandung

Sutisna. .2002.. Perilaku Konsumen dan Komunikasi Pemasaran, editor: Miftah F. Rackmat, cetakan kedua,PT. Remaja Rosda Karya Bandung.

Tjiptono. F..2004.. Manajemen Jasa .Andi Yogyakarta

Wibisono, D. 2000. Riset Bisnis. Edisi pertama.: BPFE. Yogyakarta 